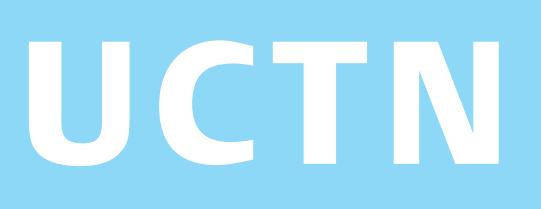

\title{
A Meckel's diverticulum with an ileal ulcer detected with double-balloon enteroscopy
}

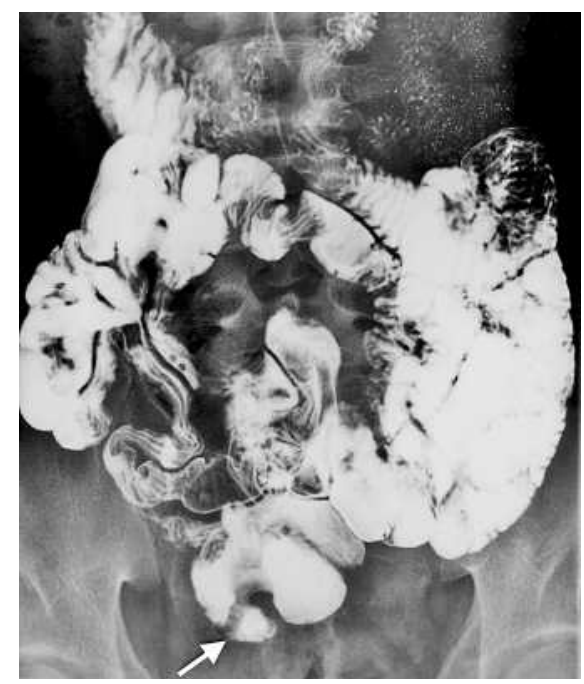

Figure 1 A 34-year-old man with iron-deficiency anemia was referred to hospital due to an ileal lesion (arrow) that had been detected on barium-meal radiography. Previous upper and lower gastrointestinal endoscopy examinations had not identified a bleeding site.

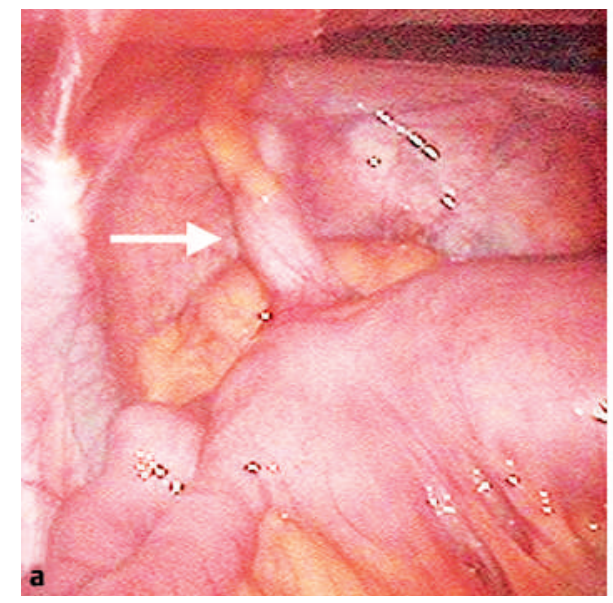

Figure 3 a At laparoscopy, the diverticulum found at $80 \mathrm{~cm}$ from the ileocecal valve on the antimesenteric side of the ileum (arrow) was surgically resected. $\mathbf{b}$ The macroscopic view of the specimen shows a Meckel's diverticulum

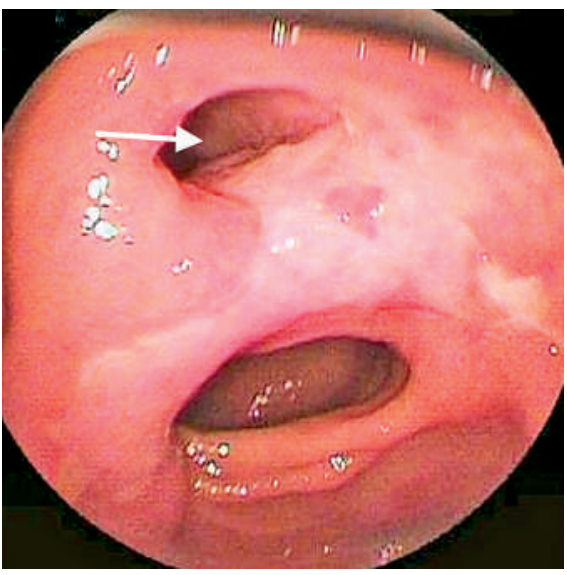

Figure 2 He underwent a peranal double-balloon enteroscopy (DBE) examination with a Fujinon EN-450P5/20 scope (Fujinon-Toshiba Inc., Tokyo, Japan). DBE revealed a diverticulum (arrow) and an ileal ulcer.

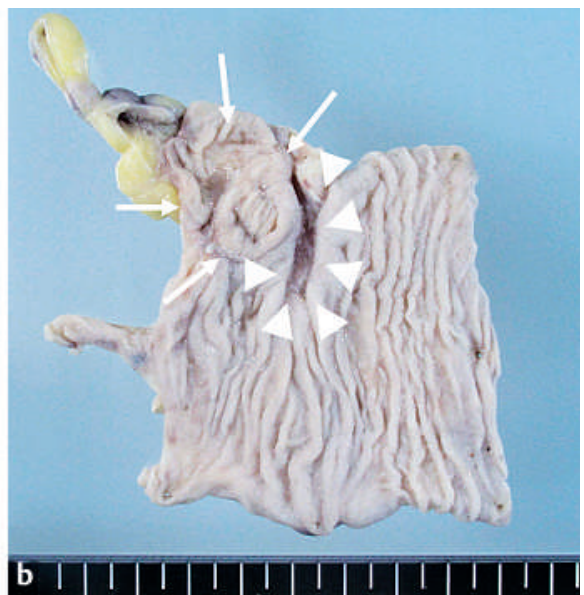

$3 \times 2 \mathrm{~cm}$ in size (arrows), accompanied by an ileal ulcer (arrowheads). The histological assessment did not identify any ectopic tissue inside the diverticulum. After the operation, the patient's anemia improved.
K. Honda ${ }^{1}$, T. Mizutani' ${ }^{1}$, N. Higuchi' ${ }^{1}$,

K. Kanayama ${ }^{1}$, Y. Sumida ${ }^{1}$, S. Yoshinaga ${ }^{1}$, S. Itaba', H. Akiho', R. Yoshimura'2,

K. Nakamura ${ }^{1}$, T. Ueki ${ }^{3}$, Y. Miyasaka ${ }^{4}$,

R. Takayanagi ${ }^{1}$

${ }^{1}$ Dept. of Medicine and Bioregulatory Science, Graduate School of Medical Sciences, Kyushu University, Fukuoka, Japan

${ }^{2}$ Hakuaikai Medical Association, Human Wellness Center, Fukuoka, Japan

${ }^{3}$ Dept. of Surgery and Oncology, Graduate School of Medical Sciences, Kyushu University, Fukuoka, Japan

${ }^{4}$ Dept. of Anatomic Pathology, Graduate School of Medical Sciences, Kyushu University, Fukuoka, Japan

Endoscopy_UCTN_Code_CCL_1AC_2AD

Corresponding author

\section{K. Nakamura, M.D., Ph.D.}

Dept. of Medicine and Bioregulatory Science

Graduate School of Medical Sciences Kyushu University

3-1-1 Maidashi, Higashi-ku

Fukuoka 812-8582

Japan

Fax: $\quad+81-92-642-5287$

Email: knakamur@intmed3.med. kyushu-u.ac.jp 